Reprod. Nutr. Dévelop., 1988, 28 Suppl. n 1, $91-92$

\title{
Fermentescibilité des constituants pariétaux de divers produits lignocellulosiques
}

\author{
J. L. BARRY, S. GUENEAU, Agnès DAVID, C. BONNET, Françoise KOZLOWSKI
}

Laboratoire de Technologie appliquée à la Nutrition, I.N.R.A., B.P. 527, 44026 Nantes Cedex 03, France.

Summary. Nine cell-wall rich by-products of various origin have been analyzed for their cell-wall neutral sugars and lignin contents and fermentated for $48 \mathrm{~h}$ in a Rusitec. Lignin can predict digestibility of dry matter $(r=0.88)$ and cellulose $(r=0.81)$. Hemicellulose fermentability does not depend on lignin content, but on their sugar composition.

Le présent travail consiste en l'étude de la fermentescibilité en milieu de rumen d'un ensemble de sous-produits riches en constituants pariétaux finement analysés afin d'identifier les paramètres analytiques expliquant les variations de leur dégradabilité.

Matériel et méthodes. Neuf sous-produits d'origine botanique variée, riches en parois cellulaires (pulpes d'agrume et de betterave, téguments (coques) de soja, de colza et de tournesol, son de blé, tourteau de palmiste, paille de blé, et drèches de maïs) ont été retenus. Leur fermentescibilité a été mesurée sur $48 \mathrm{~h}$ en Rusitec (Czerkawski et Breckenridge, 1977). Sur les matières premières et les résidus de fermentation, les oses des hémicelluloses et de la cellulose ont été analysés par chromatographie après hydrolyse (Hoebler et al., 1989) ; la teneur en lignine a été estimée (Goering et Van Soest, 1970).

Résultats et discussion. La composition des hémicelluloses (tabl. 1) varie selon les substrats. Les pulpes d'agrume et de betterave et les coques de soja contiennent des arabinogalactanes. Les issues de céréales sont riches en arabinoxylanes. Le tourteau de palmiste contient des mannanes. Les teneurs élevées en rhamnose des pulpes d'agrume et de betterave, des coques de colza, de soja et de tournesol reflètent la présence de pectines. La fermentescibilité des hémicelluloses et de la cellulose varie dans de larges proportions (tabl. 2). La dégradabilité des hémicelluloses est généralement plus élevée que celle de la cellulose. La teneur en lignine ( $\mathrm{Li}$ ) explique une part importante des variations de la fermentescibilité de la MS $\left(=85,3 \times \mathrm{Li}^{-0.35}, \mathrm{r}=0,88, \mathrm{ETR}=1,87\right)$ et de la cellulose $\left(=77,2 \times \mathrm{Li}^{-0,33}, \mathrm{r}=0,81, \mathrm{ETR}=2,85\right)$. En revanche, la fermentescibilité des hémicelluloses varie sans relation avec la teneur en lignine, mais en fonction de la nature de leurs monomères. Le mannose, bien que résistant aux attaques acides (Barry et al., 1987), et le galactose, quand ils sont présents en quantités appréciables, sont généralement fermentescibles. La fermentescibilité de l'arabinose est faible dans les issues de céréales. Celle du xylose est faible dans 
tous les substrats étudiés. La dégradabilité élevée du rhamnose, s'il est présent en quantités appréciables, traduit une fermentescibilité généralement élevée des pectines, même dans les substrats peu fermentescibles.

TABL. 1. - Caractéristiques biochimiques des constituants pariétaux des différents substrats (\% MS).

\begin{tabular}{|c|c|c|c|c|c|c|c|c|c|}
\hline & $\begin{array}{c}\text { Pulpe } \\
\text { d'agrume }\end{array}$ & $\begin{array}{c}\text { Pulpe } \\
\text { de } \\
\text { betterave }\end{array}$ & $\begin{array}{c}\text { Coques } \\
\text { de } \\
\text { soja }\end{array}$ & $\begin{array}{c}\text { Coques } \\
\text { de } \\
\text { tournesol }\end{array}$ & $\begin{array}{c}\text { Coques } \\
\text { de } \\
\text { colza }\end{array}$ & $\begin{array}{c}\text { Tourteau } \\
\text { de } \\
\text { palmiste }\end{array}$ & Paille & Son & $\begin{array}{c}\text { Drèches } \\
\text { de } \\
\text { mais }\end{array}$ \\
\hline Rhamnose $\left({ }^{1}\right)$ & 1,1 & 1,1 & 0,7 & 0,8 & 0,6 & 0,1 & 0,2 & 0,1 & 0,1 \\
\hline Arabinose & 4,6 & 16,5 & 4,7 & 2,1 & 5,4 & 1,3 & 2,3 & 8,6 & 5.8 \\
\hline Xylose & 2,0 & 1,5 & 8,2 & 12,1 & 1,5 & 2,6 & 18,2 & 14,9 & 9,1 \\
\hline Mannose & 1,3 & 1,1 & 5,8 & 1,0 & 0,5 & 39,0 & 0,7 & 0,5 & 0,5 \\
\hline Galactose & 3,2 & 4,3 & 2,9 & 0,9 & 1,9 & 2,0 & 0,8 & 0,9 & 1,6 \\
\hline Hémicelluloses $\left({ }^{2}\right)$ & 12,2 & 24,4 & 22,2 & 16,8 & 9,9 & 45,0 & 22,9 & 24,9 & 17,1 \\
\hline Cellulose $\left({ }^{3}\right)$ & 13,5 & 18,8 & 34,9 & 22,8 & 8,3 & 8,5 & 35,4 & 11,7 & 18,3 \\
\hline Lignine & 1,2 & 2,0 & 2,0 & 21,2 & 21,0 & 12,2 & 8,6 & 3,9 & 1,4 \\
\hline
\end{tabular}

$\left({ }^{1}\right)$ Les oses sont considérés sous leur forme polymérique; $\left({ }^{2}\right)$ Somme des oses hors glucose;

(3) Glucose pariétal.

TABL. 2. - Fermentescibilité de la matière sèche (MS) et des polysaccharides pariétaux (\%).

\begin{tabular}{lccccccccc}
\hline & $\begin{array}{c}\text { Pulpe } \\
\text { d'agrume }\end{array}$ & $\begin{array}{c}\text { Pulpe } \\
\text { de } \\
\text { betterave }\end{array}$ & $\begin{array}{c}\text { Coques } \\
\text { de } \\
\text { soja }\end{array}$ & $\begin{array}{c}\text { Coques } \\
\text { de } \\
\text { tournesol }\end{array}$ & $\begin{array}{c}\text { Coques } \\
\text { de } \\
\text { colza }\end{array}$ & $\begin{array}{c}\text { Tourteau } \\
\text { de } \\
\text { palmiste }\end{array}$ & Paille & $\begin{array}{c}\text { Son } \\
\text { Drèches } \\
\text { de } \\
\text { maïs }\end{array}$ \\
\hline MS & 78,4 & 67,8 & 69,1 & 19,7 & 33,5 & 48,6 & 24,0 & 59,0 & 67,3 \\
Rhamnose & 91,3 & 82,9 & 83,0 & 50,1 & 80,6 & 15,8 & $-10,1$ & 23,6 & 54,2 \\
Arabinose & 94,6 & 92,2 & 80,9 & 40,9 & 74,1 & 53,2 & 44,8 & 29,2 & 50,8 \\
Xylose & 57,5 & 45,4 & 67,2 & 14,1 & 64,7 & $-8,0$ & 34,9 & 58,3 & 41,3 \\
Mannose & 80,6 & 70,0 & 95,7 & 69,1 & 60,5 & 75,7 & 55,1 & 73,3 & 63,5 \\
Galactose & 91,3 & 87,5 & 92,0 & 54,0 & 52,0 & 62,1 & 33,6 & 46,2 & 43,7 \\
Hemicelluloses & 89,9 & 87,4 & 81,2 & 24,3 & 68,0 & 69,3 & 38,3 & 47,8 & 45,7 \\
Cellulose & 80,1 & 66,7 & 67,9 & 18,6 & 45,9 & 35,2 & 41,7 & 34,1 & 73,2 \\
\hline
\end{tabular}

La lignine est un bon prédicteur de la digestibilité de la MS, résultat en accord avec ceux de Giger et al. (1986), mais un mauvais prédicteur de la fermentescibilité des polyosides pariétaux, notamment des hémicelluloses dont la nature semble jouer un rôle essentiel.

Barry J. L., El Bouami A., Hoebler C., 1987. Reprod. Nutr. Dévelop., 27, 249-250.

Czerkawski J. W., Brekenridge G., 1977. Br. J. Nutr., 38, $371-384$.

Giger S., Sauvant D., Hervieu J., Dorléans M., 1986. Ann. Zootech., 35, 137-160.

Goering H. K., Van Soest P. J., 1970. USDA ARS Agr. Handbook, 379, 20 p.

Hoebler C., Barry J. L., David A., Delort-Laval J., 1989. J. agric. Food Chem. (sous presse). 